Matej Đuranović

Martina Rauch

Antun Galović

Marija Živić $\bowtie$

https://doi.org/10.21278/TOF.45Si1005721

ISSN 1333-1124

eISSN 1849-1391

\title{
EXERGY ANALYSIS OF AN AIR CONDITIONING PROCESS
}

\begin{abstract}
Summary
The exergy analysis of an air conditioning process in wintertime is presented in this paper. This process consists of mixing outdoor air with conditioned air, heating, humidifying, and reheating the air mixture. The air is heated in the heat exchangers by warm water at a temperature of $80 / 60^{\circ} \mathrm{C}$ and humidified by spraying water at a temperature of $12^{\circ} \mathrm{C}$. The ratio of the mass flow rates of outdoor and conditioned air is varied, and it is upon this variable that the exergy analysis is performed. The five cases are analyzed with different outdoor air temperature values. It is shown that the heat transfer rate in the heat exchangers is the smallest at the ratio of mass flow rates of outdoor and conditioned air $g_{1}=0.45$. The greatest exergy destruction is apparent in the heat exchangers, and the maximum exergy efficiency of the whole process $\varepsilon_{\mathrm{ex}}=0.71$ is achieved at the ratio $g_{1}=0.45$. According to the exergy criterion, this air conditioning is a relatively efficient process.
\end{abstract}

Key words: $\quad$ air conditioning, exergy destruction, exergy efficiency

\section{Introduction}

Heating, ventilating, and air conditioning (HVAC) systems provide thermal comfort and acceptable air quality in offices and homes. These systems currently account for approximately $20 \%$ of total energy consumption [1]; effective use of energy is an important goal in many countries worldwide. Psychrometrics is defined as the study of moist air, which is a mixture of dry air and moisture. It is used not only in heating and cooling processes to ensure the comfort of buildings' occupants but also in building insulation and roofing of properties, and it ensures the stability, deformation, and fire resistance of building materials [2]. Exergy represents quantitatively useful energy or the possibility of performing or receiving the work of different streams (mass, heat, work) flowing through the system [3]. Exergy analysis is used to detect and quantify the causes of the thermodynamic imperfection of the process being considered and points to the possibility of its thermodynamic improvement [4]. The application of exergy methods to technologies of heating, refrigerating, and air conditioning can provide a better understanding of their behaviors and enhanced tools for improving them. 
Today, exergy analysis of psychrometric processes can be found in the relevant literature. For example, Qureshi et al. [5] presented a parametric study of various HVAC processes by applying exergy analysis and defined second-law efficiency of the processes to quantify the irreversible losses. They demonstrated that these processes should be performed as they are because the measures to reduce exergy destruction are not economically feasible. Ratlamwala and Dincer [6] studied five key psychometric processes, including heating or cooling, heating with humidification, cooling with dehumidification, evaporative cooling, and adiabatic mixing. They proposed two definitions of energy and exergy efficiencies and compared these efficiencies with the third definition taken from the literature. They showed that different definitions of efficiencies give varying results that are far removed from each other.

Franconi and Brandemuehl [7] used exergy analysis to compare the exergy performance of two types of air conditioning systems: constant air volume (CAV) systems and variable air volume (VAV) systems. They showed that the latter has advantages over the former because of the reduced exergy destruction in cooling coils, reheat coils, and fans. Ghazikhani et al. [8] compared the two methods of humidification, constant enthalpy humidification $(\mathrm{CEH})$ and constant temperature humidification $(\mathrm{CTH})$, in an HVAC system. They quantified the difference between the amount of exergy consumption and exergy loss with these methods, concluding that exergy consumption in an HVAC obtained by CEH is less than in one obtained by CHT. Caliskan et al. [9] applied energy and exergy analyses and sustainability assessment to one novel and three conventional types of air-cooling systems located in the same building. They showed that at the dead-state temperatures of higher than $23^{\circ} \mathrm{C}$ (comfort temperature), exergy efficiency and sustainability of the novel system, which is based on the novel Maisotsenko cycle, are higher than those of the conventional systems. Sakulpipatsin et al. [10] demonstrated the pertinence of the exergy concept for the design of buildings and HVAC systems so that the concept can be applied in these areas properly. Although they did not perform exergy research on integration between buildings and HVAC systems, they concluded that this would be an interesting topic for further research.

In this study, the first and second laws of thermodynamics are applied to the air conditioning process. The heat transfer rate and exergy destructions are observed according to the process parameter, namely the ratio of the mass flow rate of outdoor air to the total mass flow rate of moist air, for the five cases in which the outdoor air temperature values differ.

\section{Mathematical model}

The air conditioning process under investigation consists of the following: 1-2 adiabatic mixing of outdoor with conditioned air in specified ratios, 3-4 heating of the air mixture to a state suitable for humidification, 4-5 adiabatic humidification by spraying water, and 5-6 reheating of the air mixture to the state in which it is inserted into the air-conditioned space. The entire process is shown in the Mollier $h, x$ diagram in Figure 1. As can be seen, all states of the moist air are placed in the unsaturated region. The water vapor in the moist air is superheated; the partial pressure of water vapor in the moist air is less than the saturation pressure. 

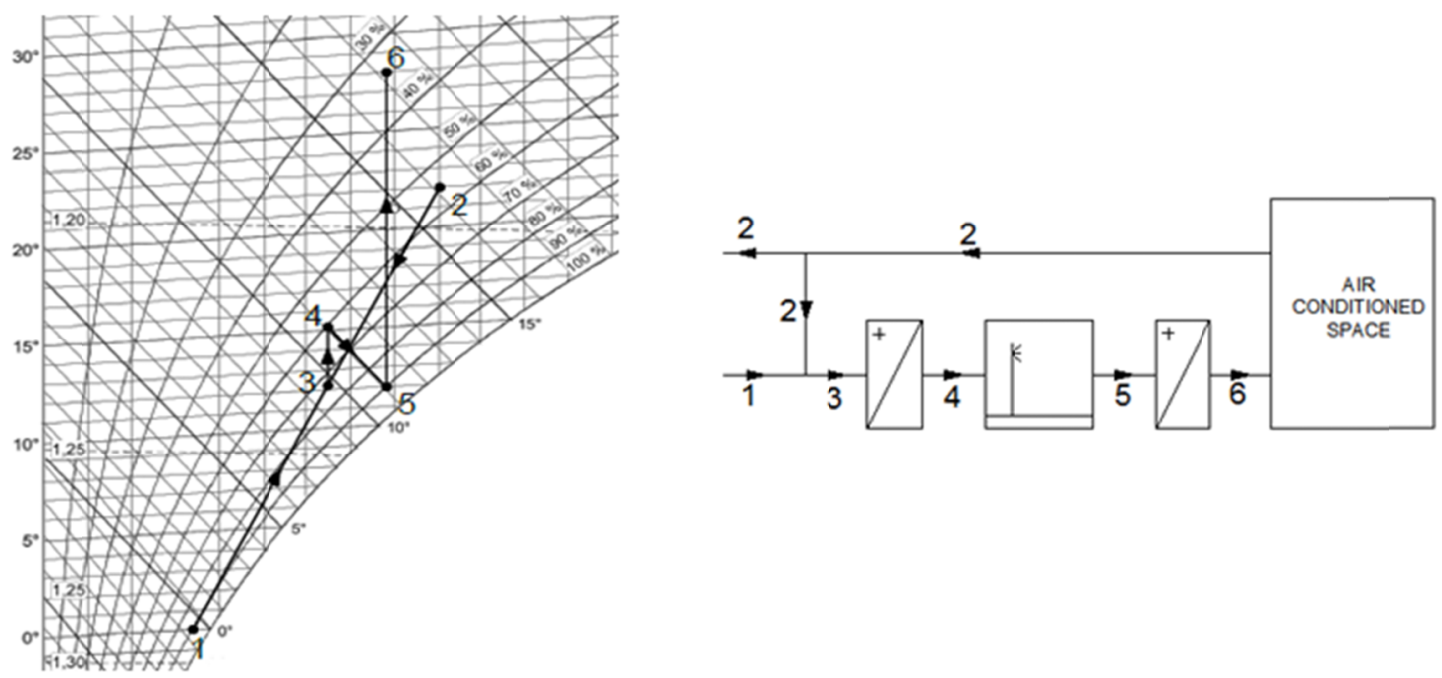

Fig. 1 Process in Mollier- $h, x$-diagram and shematic of the process

In the considered process, the thermal states of the moist air are specified: 1 - state of the outdoor air, 2-state of the air in the air-conditioned space, and 6-state of the air in which it is inserted into the air-conditioned space. The outdoor air is at the temperature $\vartheta_{1}=0^{\circ} \mathrm{C}$ and relative humidity $\varphi_{1}=90 \%$; the state of the air in the air-conditioned space is determined to be at temperature $\vartheta_{2}=22^{\circ} \mathrm{C}$ and $\varphi_{2}=55 \%$, while the state of the air getting into the space is determined to be at temperature $\vartheta_{6}=28^{\circ} \mathrm{C}$ and specific humidity $x_{6}=x_{5}$. The volume flow rate of the air in this state is $1000 \mathrm{~m}^{3} / \mathrm{h}$. After humidification, the state of the air at 5 is determined to be $\vartheta_{5}=12^{\circ} \mathrm{C}$ and $\varphi_{5}=90 \%$. Humidification is performed by spraying water at temperature $\vartheta_{\mathrm{w}}=12^{\circ} \mathrm{C}$. The state of the air after the first heating (state 4 ) is calculated from the mass balance of the mixing chamber and the law of humidification. The ratio of the mass flow rate of outdoor air to the total mass flow rate of the air in the process varies from 0.45 to 1.0 . The total pressure of the air in all states is $p=1$ bar. The environmental state is the state of outdoor air at the pressure $p_{0}=1 \mathrm{bar}$, temperature $\vartheta_{0}=0^{\circ} \mathrm{C}$, and relative humidity $\varphi_{0}=90 \%$. Heating of the air is carried out in heat exchangers using warm water of temperature $80 / 60^{\circ} \mathrm{C}\left(\vartheta_{\mathrm{w} 1}=80^{\circ} \mathrm{C}, \vartheta_{\mathrm{w} 2}=60^{\circ} \mathrm{C}\right)$.

Calculation of the physical quantities, which determine the states of the moist air, is performed using the equations given below.

Specific enthalpy of the moist air is defined by the following equation:

$$
h_{1+\mathrm{x}}=c_{\mathrm{pa}} \vartheta+x\left(r_{0}+c_{\mathrm{pv}} \vartheta\right) .
$$

Specific exergy of the moist air is defined as follows [8]:

$$
\begin{aligned}
& e x_{1+\mathrm{x}}=\left(c_{\mathrm{pa}}+x c_{\mathrm{pv}}\right) T_{0}\left(\frac{T}{T_{0}}-1-\ln \frac{T}{T_{0}}\right)+ \\
& +(1+\kappa) R_{\mathrm{a}} T_{0} \ln \frac{p}{p_{0}}+R_{\mathrm{a}} T_{0}\left[(1+\kappa) \ln \frac{1+\kappa_{0}}{1+\kappa}+\kappa \ln \frac{\kappa}{\kappa_{0}}\right] .
\end{aligned}
$$

Specific humidity is expressed by the equation:

$$
x=\frac{m_{\mathrm{v}}}{m_{\mathrm{a}}}=0.622 \frac{\varphi p_{\mathrm{s}}(T)}{p-\varphi p_{\mathrm{s}}(T)} .
$$


Molar humidity is defined thus:

$$
\kappa=\frac{n_{\mathrm{v}}}{n_{\mathrm{a}}}=\frac{\varphi p_{\mathrm{s}}(T)}{p-\varphi p_{\mathrm{s}}(T)} .
$$

The vapor pressure of water in saturated moist air (in $\mathrm{Pa}$ ) is expressed by the following equation [11]:

$$
\begin{aligned}
& p_{s}(T)=\exp \left(C_{1} / T+C_{2}+C_{3} T+C_{4} T^{2}+C_{5} T^{3}+C_{6} \ln T\right) \\
& C_{1}=-5.8002206 * 10^{3} \\
& C_{2}=1.3914993 \\
& C_{3}=-4.8640239 * 10^{-2} \\
& C_{4}=4.1764768 * 10^{-5} \\
& C_{5}=-1.4452093 * 10^{-8} \\
& C_{6}=6.5459673 .
\end{aligned}
$$

in which the temperature should be inserted in $\mathrm{K}$.

Specific exergy of water used for humidification or heating the moist air is defined by:

$$
e x_{\mathrm{w}}=c_{\mathrm{w}}\left(T_{\mathrm{w}}-T_{0}-T_{0} \ln \frac{T_{\mathrm{w}}}{T_{0}}\right)
$$

Equation (3) shows that the mass of the water vapor in the moist air is reduced to the mass of dry air because the latter is constant here, as is the case in most psychometric processes. Other given quantities, expressed by equations (1) and (2), are also reduced to a kilogram of dry air.

Equation (2), which expresses the specific exergy of the moist air, consists of three terms that represent three potentials: thermal, mechanical, and chemical. The first term represents the exergy contribution of dry air and superheated vapor due to the different temperature of moist air in relation to the environment, the second term represents exergy contribution due to differing pressure of moist air in relation to the environment, while the third term represents the contribution caused by the different chemical composition of moist air and environmental air.

\subsection{Mass energy analysis}

Mass energy analysis of the process takes into account the laws of conservation of mass and conservation of energy. The mass flow rate of dry air, in the considered process of air conditioning, is constant and is determined using the quantities given for state 6 . From the equation of mixing the outdoor air with conditioned air, we follow the ratio of mass flow rate of outdoor air to the total mass flow rate of moist air:

$$
g_{1}=\frac{q_{\mathrm{m} 1}}{q_{\mathrm{m}}}=\frac{q_{\mathrm{m} 1}}{q_{\mathrm{m} 1}+q_{\mathrm{m} 2}} .
$$

The specific enthalpy of the air mixture follows from the energy conservation law applied to the adiabatic mixing chamber and is equal to:

$$
\left(h_{1+\mathrm{x}}\right)_{3}=g_{1}\left(h_{1+\mathrm{x}}\right)_{1}+\left(1-g_{1}\right)\left(h_{1+\mathrm{x}}\right)_{2} .
$$

Specific humidity in the air in state 3 follows from the mass conservation law and is equal to:

$$
x_{3}=g_{1} x_{1}+\left(1-g_{1}\right) x_{2} .
$$


Specific enthalpy of the moist air in state 4 is obtained from the law of humidity by spraying water of specific enthalpy $h_{\mathrm{w}}$ :

$$
\left(h_{1+\mathrm{x}}\right)_{4}=\left(h_{1+\mathrm{x}}\right)_{5}-\left(x_{5}-x_{4}\right) h_{\mathrm{w}}=\left(h_{1+\mathrm{x}}\right)_{5}-\left(x_{5}-x_{4}\right) c_{\mathrm{w}} \vartheta_{\mathrm{w}} .
$$

Mass flow rate of the liquid water is calculated according to this equation:

$$
q_{\mathrm{mw}}=q_{\mathrm{m}}\left(x_{5}-x_{4}\right) .
$$

Heat transfer rate of the first heat exchanger (HE1) is defined by:

$$
\Phi_{\mathrm{HE} 1}=\Phi_{3-4}=q_{\mathrm{m}}\left(\left(h_{1+\mathrm{x}}\right)_{4}-\left(h_{1+\mathrm{x}}\right)_{3}\right) .
$$

Mass flow rate of warm water, which is used for moist air heating in the first heat exchanger, is equal to:

$$
q_{\mathrm{mw} 1}=\frac{\Phi_{\mathrm{HE} 1}}{c_{\mathrm{w}}\left(T_{\mathrm{w} 1}-T_{\mathrm{w} 2}\right)}=\frac{q_{\mathrm{m}}\left(\left(h_{1+\mathrm{x}}\right)_{4}-\left(h_{1+\mathrm{x}}\right)_{3}\right)}{c_{\mathrm{w}}\left(T_{\mathrm{w} 1}-T_{\mathrm{w} 2}\right)} .
$$

Heat transfer rate of the second heat exchanger (HE2) is defined by:

$$
\Phi_{\mathrm{HE} 2}=\Phi_{5-6}=q_{\mathrm{m}}\left(\left(h_{1+\mathrm{x}}\right)_{6}-\left(h_{1+\mathrm{x}}\right)_{5}\right) .
$$

Mass flow rate of warm water, which is used for moist air heating in the second heat exchanger, is equal to:

$$
q_{\mathrm{mw} 2}=\frac{\Phi_{\mathrm{HE} 2}}{c_{\mathrm{w}}\left(T_{\mathrm{w} 1}-T_{\mathrm{w} 2}\right)}=\frac{q_{\mathrm{m}}\left(\left(h_{1+\mathrm{x}}\right)_{6}-\left(h_{1+\mathrm{x}}\right)_{5}\right)}{c_{\mathrm{w}}\left(T_{\mathrm{w} 1}-T_{\mathrm{w} 2}\right)} .
$$

\subsection{Exergy analysis of the process}

The air conditioning process is irreversible, which means that exergy destruction appears in the process. The causes of exergy destruction lie in the irreversibility of the mixing and heat transfer processes.

\subsubsection{Exergy destruction in the mixing chamber}

In the mixing chamber, the outdoor air flow enters at state 1 and the air flow from the air-conditioned space at state 2, and they exit the air flow at state 3 . The exergy destruction in the mixing chamber is the difference between the exergy at the chamber entrance (exergy of the air flows at states 1 and 2) and the exergy at the chamber exit (exergy of the moist air flow at state 3 ).

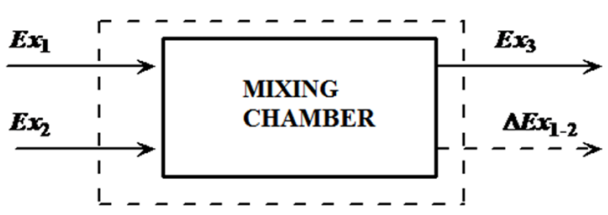

Fig. 2 Exergy destruction in the mixing chamber

$$
\Delta E x_{1-2}=g_{1} q_{\mathrm{m}}\left(e x_{1+\mathrm{x}}\right)_{1}+\left(1-g_{1}\right) q_{\mathrm{m}}\left(e x_{1+\mathrm{x}}\right)_{2}-q_{\mathrm{m}}\left(e x_{1+\mathrm{x}}\right)_{3}
$$

\subsubsection{Exergy destruction in the first heat exchanger.}

The exergy destruction in the first heat exchanger is equal to the sum of the difference of exergies of the moist air and the difference of exergies of hot water at the entrance and exit of the heat exchanger. 


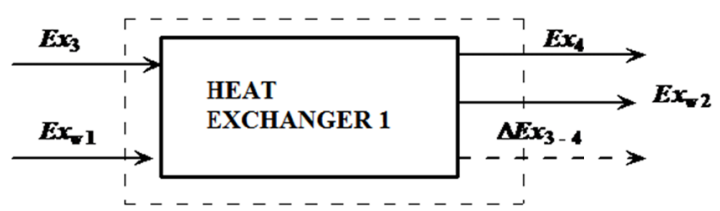

Fig. 3 Exergy destruction in the first heat exchanger

$$
\Delta E x_{3-4}=q_{\mathrm{m}}\left(\left(e x_{1+\mathrm{x}}\right)_{3}-\left(e x_{1+\mathrm{x}}\right)_{4}\right)+q_{\mathrm{mw} 1}\left(e x_{\mathrm{w} 1}-e x_{\mathrm{w} 2}\right)
$$

\subsubsection{Exergy destruction in the humidifying section.}

In the humidifying section, the moist air flow enters at state 4 , as does the spray water, and exits at state 5. The exergy destruction in the humidifying section is equal to the difference of exergies at the section's entrance and exit.

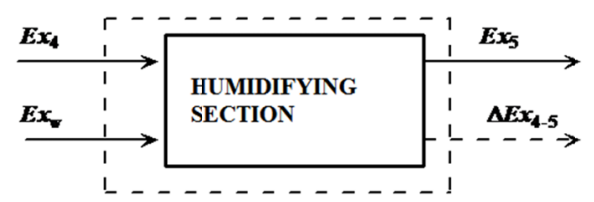

Fig. 4 Exergy destruction in the humidifying section

$$
\Delta E x_{4-5}=q_{\mathrm{m}}\left(\left(e x_{1+\mathrm{x}}\right)_{4}-\left(e x_{1+\mathrm{x}}\right)_{5}\right)+q_{\mathrm{mw}} e x_{\mathrm{w}}
$$

\subsubsection{Exergy destruction in the second heat exchanger.}

Exergy destruction in the second heat exchanger is expressed by equation (19) and shown in Figure 5:

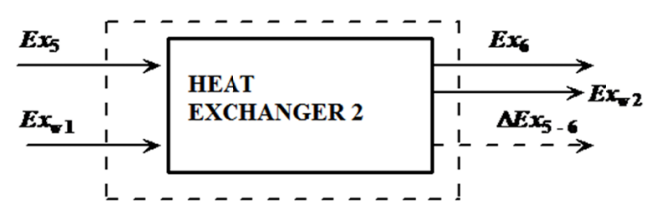

Fig. 5 Exergy destruction in the second heat exchanger

$$
\Delta E x_{5-6}=q_{\mathrm{m}}\left(\left(e x_{1+\mathrm{x}}\right)_{5}-\left(e x_{1+\mathrm{x}}\right)_{6}\right)+q_{\mathrm{mw} 2}\left(e x_{\mathrm{w} 1}-e x_{\mathrm{w} 2}\right)
$$

\subsubsection{Total exergy destruction of the process.}

Exergy destruction of the entire process can be expressed by the following equation:

$$
\begin{aligned}
& \left.\Delta E x_{1-6}=q_{\mathrm{m}}\left[g_{1}\left(e x_{1+\mathrm{x}}\right)_{1}+\left(1-g_{1}\right)\left(e x_{1+\mathrm{x}}\right)_{2}-\left(e x_{1+\mathrm{x}}\right)_{6}\right)\right]+ \\
& +q_{\mathrm{mw}} e x_{\mathrm{w}}+\left(q_{\mathrm{mw} 1}+q_{\mathrm{mw} 2}\right)\left(e x_{\mathrm{w} 1}-e x_{\mathrm{w} 2}\right) .
\end{aligned}
$$
system:

This is equal to the sum of exergy destructions in the elements of the air conditioning

$$
\Delta E x_{1-6}=\Delta E x_{1-2}+\Delta E x_{3-4}+\Delta E x_{4-5}+\Delta E x_{5-6} .
$$

Exergy efficiency of the entire process can be calculated, according to [12], as the ratio of the sum of exergies at the exit and sum of the exergies at the entrance.

$$
\varepsilon_{\mathrm{ex}}=\frac{q_{\mathrm{m}}\left(e x_{1+\mathrm{x}}\right)_{6}+\left(q_{\mathrm{mw} 1}+q_{\mathrm{mw} 2}\right) e x_{\mathrm{w} 2}}{q_{\mathrm{m}} g_{1}\left(e x_{1+\mathrm{x}}\right)_{1}+q_{\mathrm{m}}\left(1-g_{1}\right)\left(e x_{1+\mathrm{x}}\right)_{2}+\left(q_{\mathrm{mw} 1}+q_{\mathrm{mw} 2}\right) e x_{\mathrm{w} 1}+q_{\mathrm{mw}} e x_{\mathrm{w}}}
$$




\section{Results}

The equations of the mathematical model are implemented using Matlab software and results are shown in diagrams.

Figure 6 shows the relationship between the mass flow rate of water for humidification $q_{\mathrm{mw}}$ and the ratio of mass flow rate of outdoor air to the total mass flow rate of moist air $g_{1}$. The mass flow rate of water increases linearly with the increase in ratio $g_{1}$ and reaches maximum at $g_{1}=1.0$ (there is no mixing). In this case, the difference in specific humidity values $\left(x_{5}-x_{4}\right)$ is maximal, as is the mass flow rate of water for humidification.

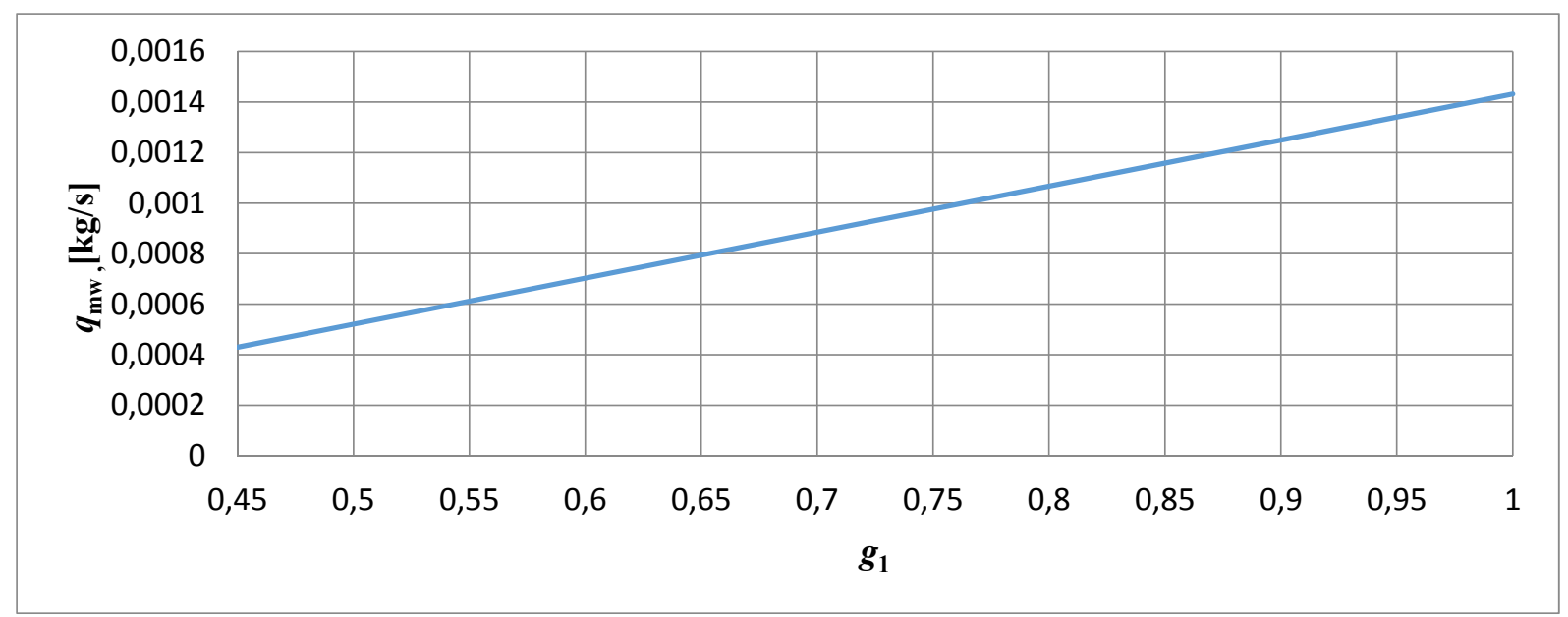

Fig. 6 Mass flow rate of water for humidification versus the ratio of mass flow rate of outdoor air to the total mass flow rate of moist air

Figure 7 shows the relationship between the heat transfer rate of both heat exchangers $\Phi_{\mathrm{HE} 1}$ and $\Phi_{\mathrm{HE} 2}$ and the ratio of mass flow rate of outdoor air to the total mass flow rate of moist air $g_{1}$. The heat transfer rate of the second heat exchanger is constant because the mass flow rate of the air in the process is also constant and the states of the air at 5 and 6 are predetermined. The heat transfer rate of the first heat exchanger $\Phi_{\mathrm{HE} 1}$ increases linearly with the increase in the ratio $g_{1}$ from $1.01 \mathrm{~kW}$ for $g_{1}=0.45$ to $7.39 \mathrm{~kW}$ for $g_{1}=1$. This is because, with the increase in the mass flow rate of the outdoor air $g_{1}$, the temperature of the air mixture or its enthalpy decreases, making it necessary to heat it to a state suitable for humidification.

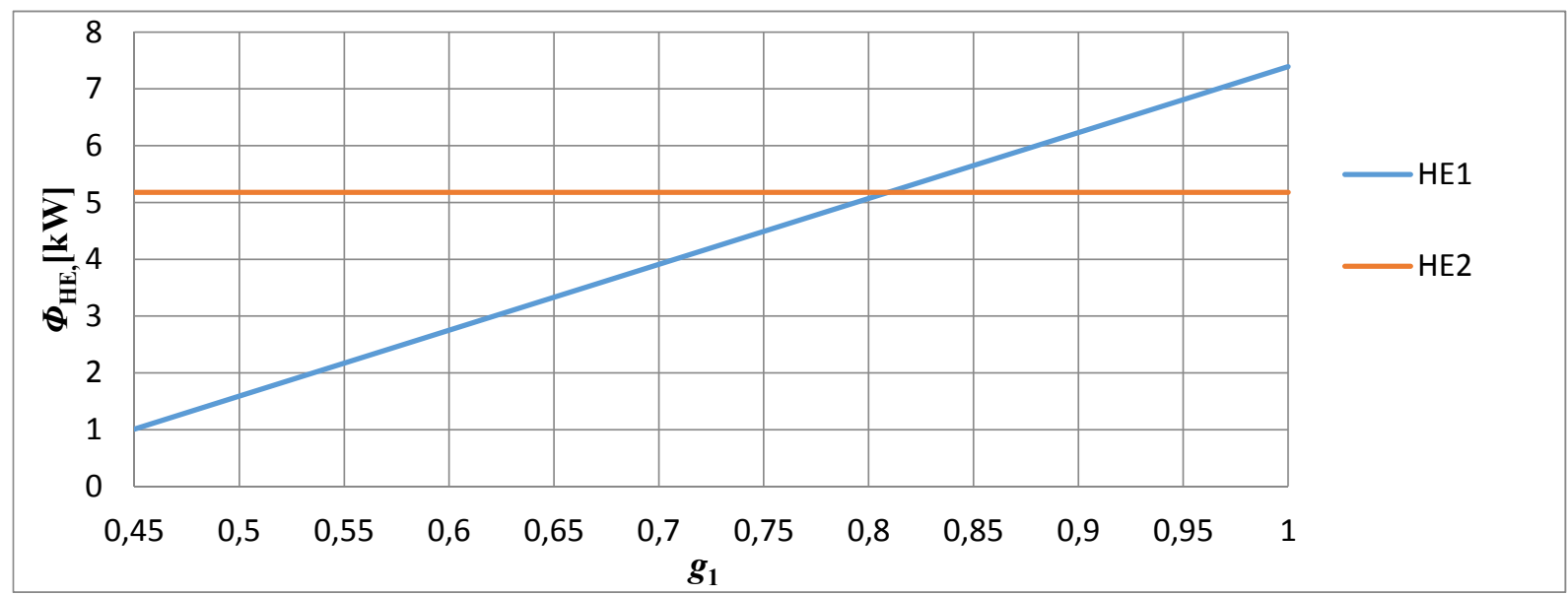

Fig. 7 Heat transfer rate of the first and second heat exchanger versus the ratio of mass flow rate of outdoor air to the total mass flow rate of moist air 
The diagram in Figure 8 shows the relationships between the exergy destructions in the mixing process of outdoor and conditioned air $\Delta E x_{1-2}$ and in the humidification process $\Delta E x_{4-5}$ and the ratio of the mass flow rate of outdoor air to the total mass flow rate of moist air $g_{1}$. The values of the exergy destructions are very small, less than $0.15 \mathrm{~kW}$. Exergy destruction in the mixing process reaches maximum at $g_{1}=0.5$ and decreases to zero at $g_{1}=1$. Exergy destruction in the humidification process continuously increases because, with the increase of the ratio of outdoor air, the exergy of water for humidification and the exergy of air at state 4 increases, but the exergy of air at state 5 is not changed.

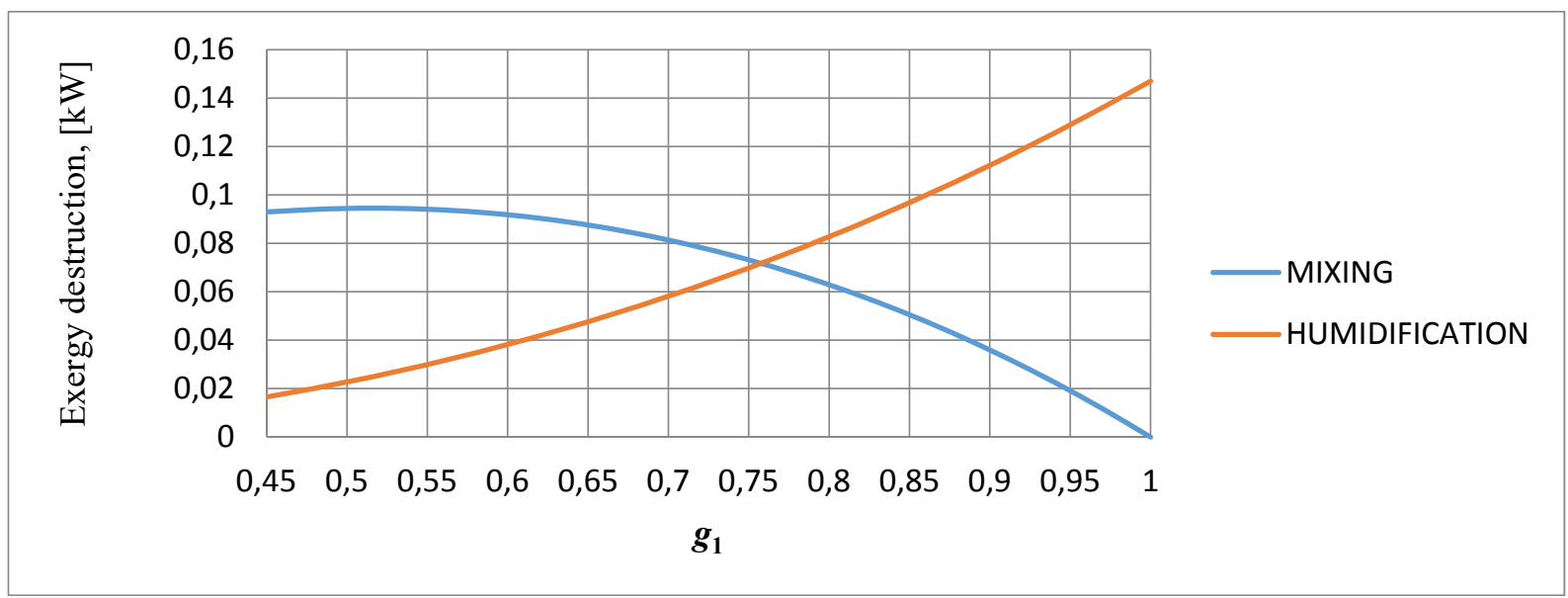

Fig. 8 Exergy destructions in the mixing and humidification processes versus the ratio of mass flow rate of outdoor air to the total mass flow rate of moist air

Figure 9 shows the relationships between the exergy destructions in the first $\Delta E x_{3-4}$ and in the second $\Delta E x_{5-6}$ heat exchanger and the ratio of mass flow rate of outdoor air to the total mass flow rate of moist air $g_{1}$. As can be seen, the values of these destructions are considerably greater than in the previous two cases. The exergy destruction in the first heat exchanger increases due to the increase of the heat transfer rate in the first heat exchanger, and in the second it is constant because the heat transfer rate of the second heat exchanger is constant.

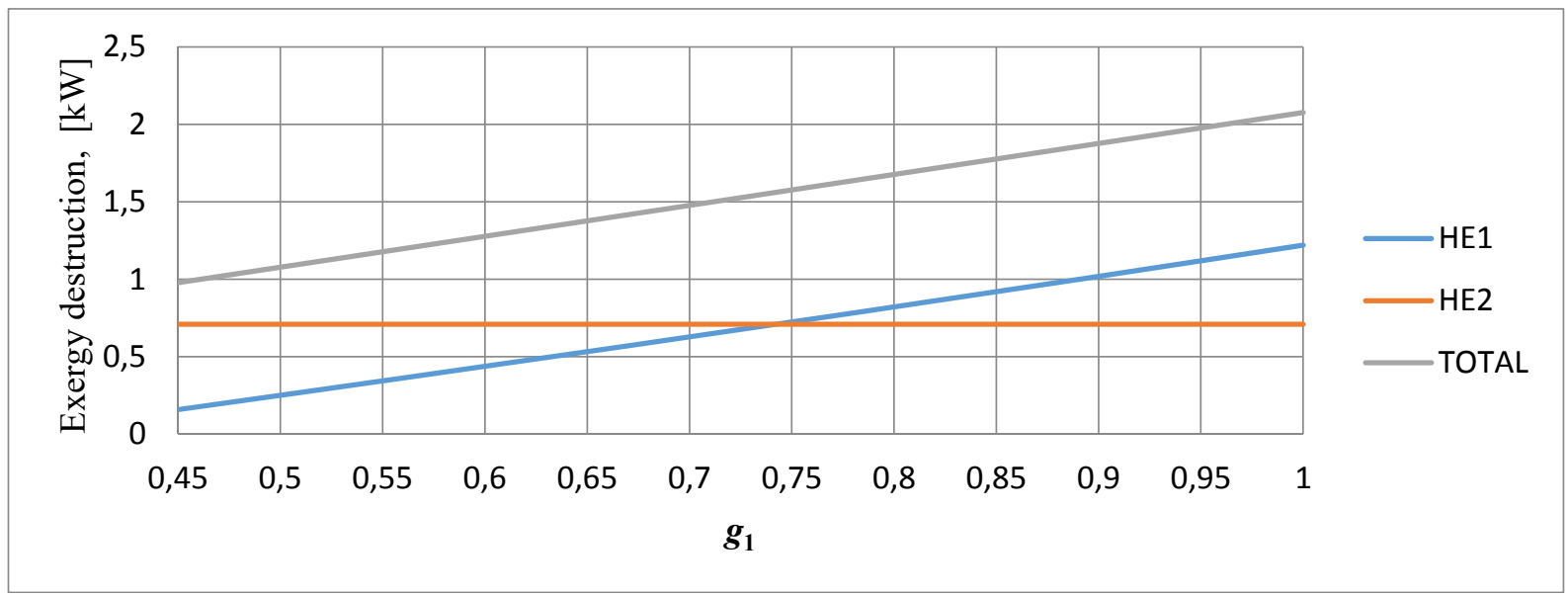

Fig. 9 Exergy destructions in the first and second heat exchanger and the total exergy destruction versus the ratio of mass flow rate of outdoor air to the total mass flow rate of moist air 
Figure 10 shows the fraction of certain exergy destruction in the total exergy destruction. Clearly, the exergy destructions in the mixing and humidification processes do not have an important effect on the total exergy destruction, while the exergy destructions in the first and second heat exchangers do have such an effect.

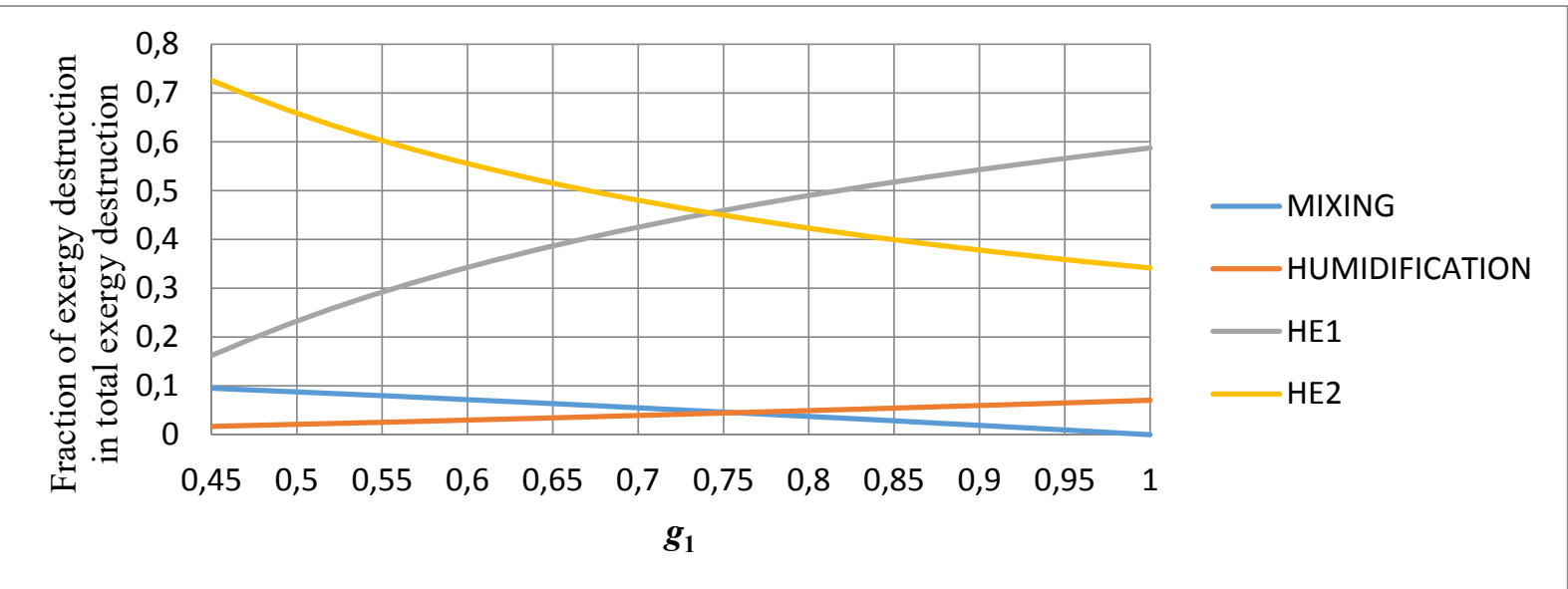

Fig. 10 Fraction of certain exergy destruction in the total exergy destruction versus the ratio of mass flow rate of outdoor air to the total mass flow rate of moist air

Figure 11 shows the relationship between exergy efficiency of the process and the ratio of mass flow rate of outdoor air to the total mass flow rate of moist air $g_{1}$. The exergy efficiency decreases with the increase of ratio $g_{1}$ from value 0.7 to 0.66 . These values are relatively high, indicating that this air conditioning process, from the viewpoint of the second law of thermodynamics, is relatively efficient.

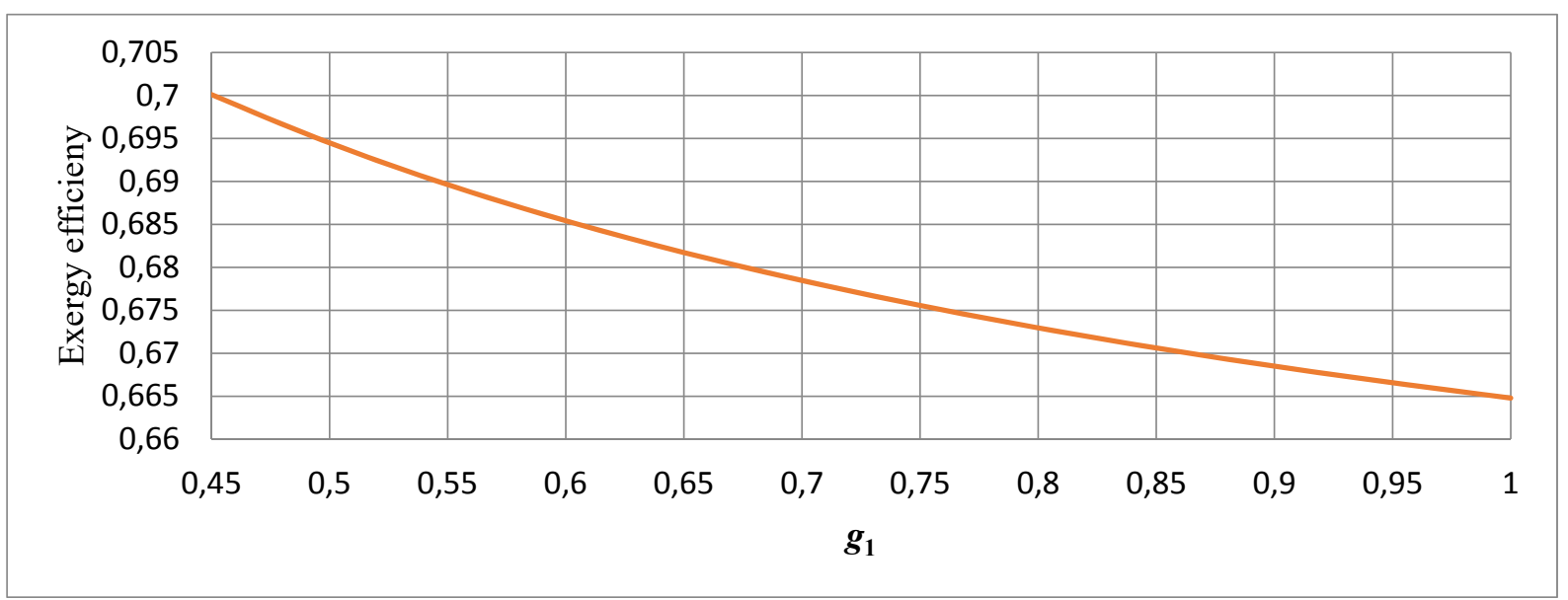

Fig. 11 Exergy efficiency versus the ratio of mass flow rate of outdoor air to the total mass flow rate of moist air

The results shown above are given for the temperature of outdoor air, $0{ }^{\circ} \mathrm{C}$. As in real life, the temperature of the outdoor air is variable; the following is an overview of the results of the considered process for different outdoor air temperature values while other parameters of the analysis remain the same. The outdoor air temperature varies from $-5{ }^{\circ} \mathrm{C}$ to $5{ }^{\circ} \mathrm{C}$ in increments of $2.5^{\circ} \mathrm{C}$. 


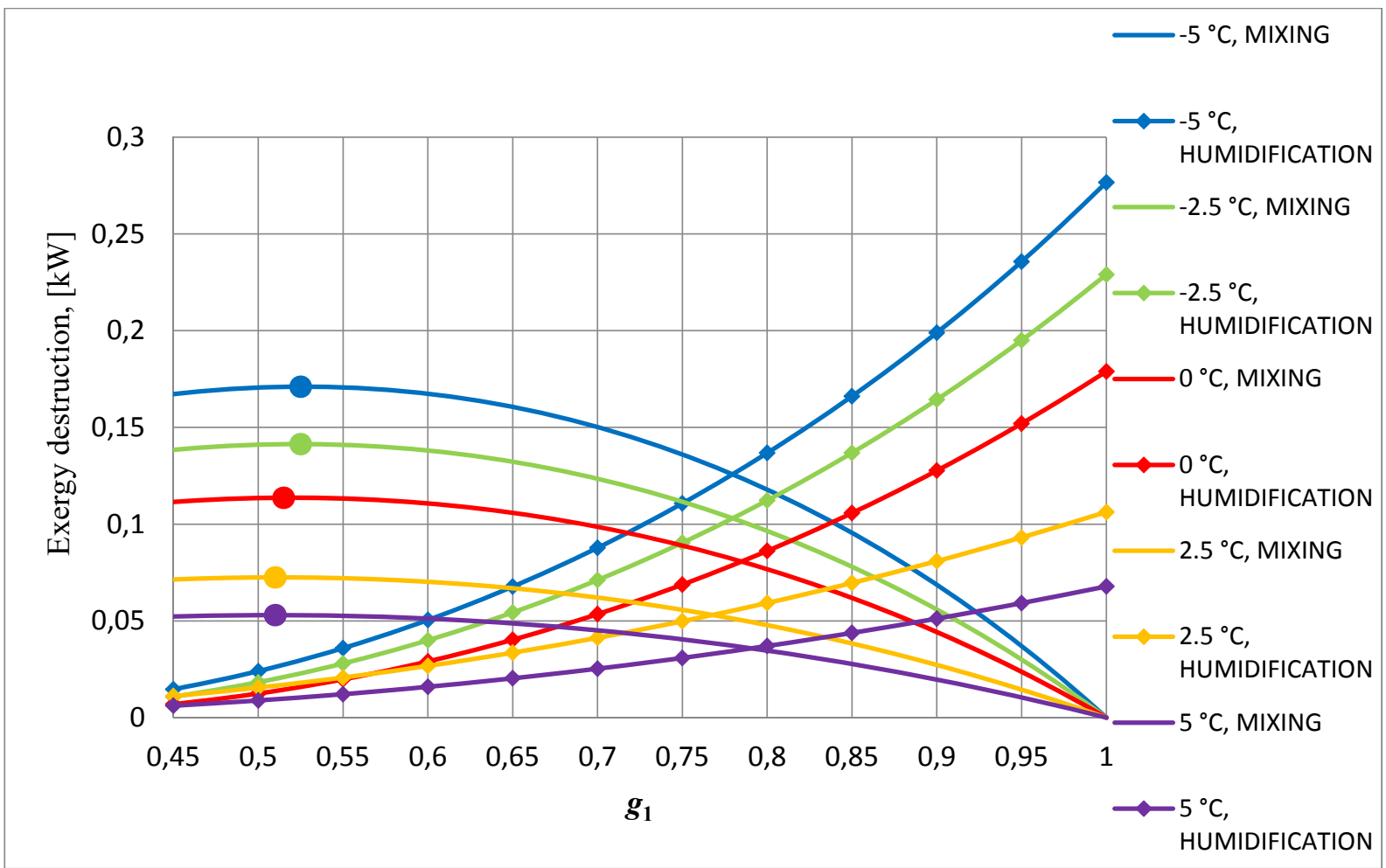

Fig. 12 Exergy destruction in mixing and humidification processes versus the ratio of mass flow rate of outdoor air to the total mass flow rate of moist air for different values of the temperature of outdoor air

Figure 12 shows exergy destructions of adiabatic mixing and humidification processes for certain outdoor air temperature values. Curves of the exergy destructions in the mixing process as well as the humidification process have a similar flow for all outdoor air temperature values. Exergy destructions in the mixing process have maxima at the ratios of mass flow rate of outdoor air to the total mass flow rate of most air from $g_{1}=0.51$ to $g_{1}=0.525$ and continue to fall to value $\Delta E x_{12}=0 \mathrm{~kW}$ for $g_{1}=1$. The values of exergy destruction in the mixing process, for the same value of ratio of mass flow rate of outdoor air to the total mass flow rate of most air, are higher at the lower values of temperature of outdoor values. The reasons are that the state of the air in the room in all cases is unchanged and that adiabatic mixing of that air with the outdoor air at lower temperature generates greater exergy destruction. Differences in the values of the exergy destruction of mixing and humidification processes are higher at lower values of the ratio $g_{1}$ because in these cases, the contribution of the irreversibility of the mixing is more pronounced than the contribution of the irreversibility of the humidification process. Exergy destructions of the humidification process show a steady increase and are higher at lower temperatures and higher values of the ratio $g_{1}$ because the growth of $g_{1}$ and the temperature drop increase the total exergy of water for humidification and the total exergy of the air at state 4 (the state before humidification), while the total exergy of the air at state 5 does not change.

Figure 13 shows total exergy destructions for different outdoor air temperature values. The total exergy destructions increase with the increase of the ratio of mass flow rate of outdoor air to the total mass flow rate of moist air and with the drop in outdoor air temperature. Accordingly, exergy efficiencies decrease with the increase of the ratio of mass flow rate of outdoor air to the total mass flow rate of moist air and with the temperature drop, as Figure 14 shows. 


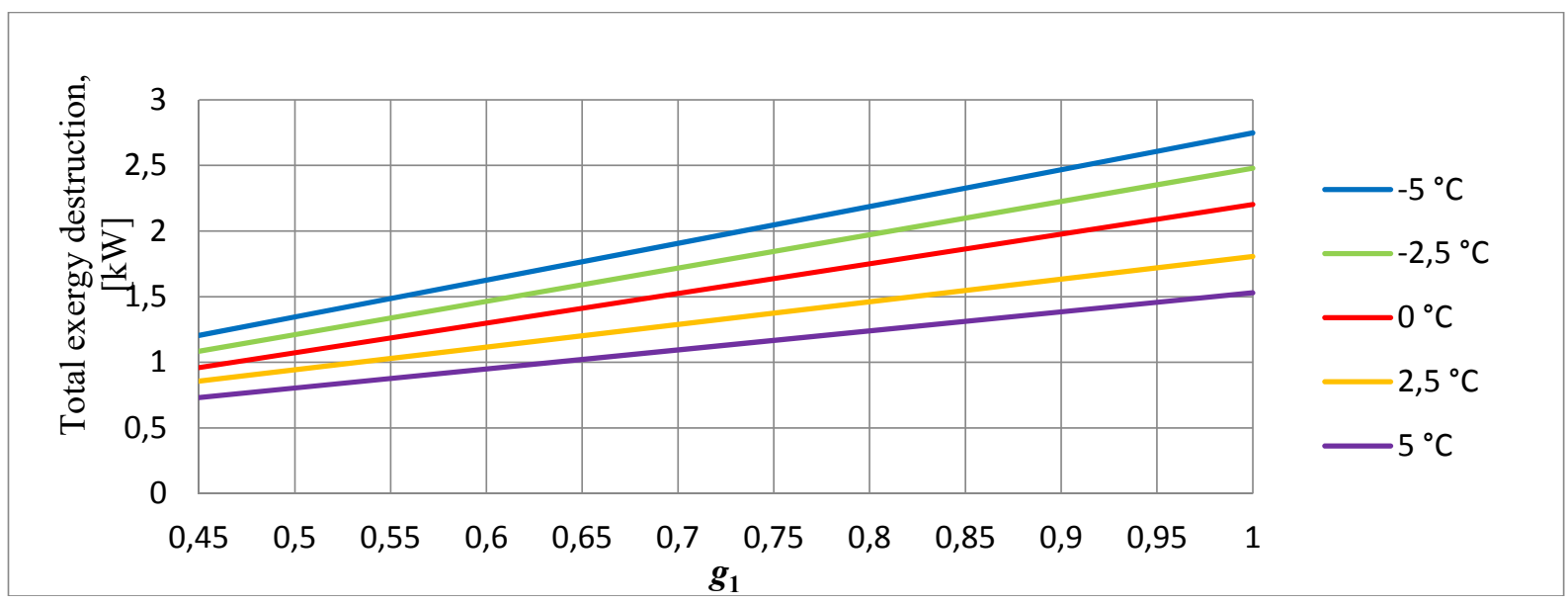

Fig. 13 Total exergy destruction versus the ratio of mass flow rate of outdoor air to the total mass flow rate of moist air for different values of the temperature of outdoor air

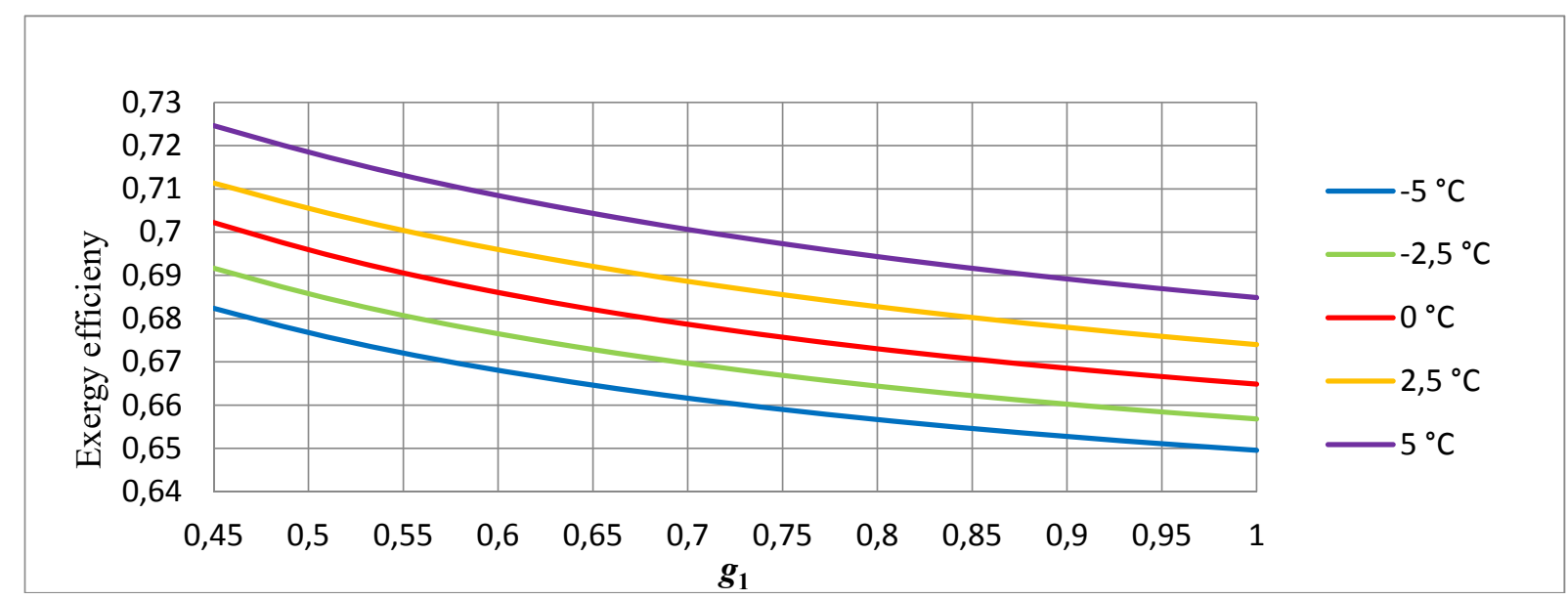

Fig. 14 Exergy efficiency versus the ratio of mass flow rate of outdoor air to the total mass flow rate of moist air for different values of the temperature of outdoor air

\section{Conclusion}

The study focused on analyzing the energy and exergy of an air conditioning process in wintertime. It showed that the mass flow rate of water for humidification and the heat transfer rate of the first heat exchanger are dependent on the ratio of mass flow rate of outdoor air to the total mass flow rate of moist air. The heat transfer in heat exchangers had a much greater effect on the total exergy destruction than did the mixing and humidification process. This air conditioning process, from the viewpoint of the second law of thermodynamics, is relatively efficient. Exergy efficiency of the process was maximal at the ratio of mass flow rate of outdoor air to the total mass flow rate of moist air 0.45 , and its value was 0.71 for the temperature of outdoor air $0{ }^{\circ} \mathrm{C}$. The process generates the least exergy destruction and consumes the least energy and water for humidification at the ratio of mass flow rate of outdoor air to the mass flow rate of moist air $g_{1}=0.45$.

\section{Nomenclature}

\begin{tabular}{|c|c|c|}
\hline$e x_{1+x}$ & $\mathrm{~J} / \mathrm{kg}$ & specific exergy of moist air \\
\hline$e x_{\mathrm{w}}$ & $\mathrm{J} / \mathrm{kg}$ & specific exergy of water \\
\hline$E x$ & W & exergy \\
\hline$g_{1}$ & $\mathrm{~kg} / \mathrm{kg}$ & $\begin{array}{l}\text { ratio of mass flow rate of outdoor air to the total } \\
\text { mass flow rate of moist air }\end{array}$ \\
\hline
\end{tabular}


A. Galović, M. Živić

$\begin{array}{ccl}h_{1+\mathrm{x}} & \mathrm{J} / \mathrm{kg} & \text { specific enthalpy of moist air } \\ p_{\mathrm{s}} & \mathrm{Pa} & \text { partial pressure of water vapor in saturated air } \\ q_{\mathrm{m}} & \mathrm{kg} / \mathrm{s} & \text { mass flow rate of air } \\ q_{\mathrm{mw}} & \mathrm{kg} / \mathrm{s} & \text { mass flow rate of water } \\ \mathrm{T} & \mathrm{K} & \text { thermodynamic temperature } \\ x & \mathrm{~kg} / \mathrm{kg} & \text { specific humidity } \\ \Delta E x & \mathrm{~W} & \text { exergy destruction } \\ \varepsilon_{\mathrm{ex}} & - & \text { exergy efficiency } \\ \vartheta & { }^{\circ} \mathrm{C} & \text { temperature } \\ \kappa & \mathrm{kmol} / \mathrm{kmol} & \text { molar humidity } \\ \Phi & \mathrm{W} & \text { heat flow rate } \\ \varphi & \mathrm{mol} / \mathrm{mol} & \text { relative humidity }\end{array}$

\section{REFERENCES}

[1] Chengqin, R., Nianping, L. and Guangfa, T., Principles of exergy analysis in HVAC and evaluation of evaporative cooling schemes, Build. Environ., Vol. 37, pp 1045-1055, 2002. https://doi.org/10.1016/s0360-1323(01)00104-4

[2] Ghosh, S. and Dincer, I., Development and performance assessment of a new integrated system for HVAC\&R applications, Energy, Vol. 80, pp 159-167, 2015. https://doi.org/10.1016/j.energy.2014.11.057

[3] Bejan, A., Fundamentals of exergy analysis, entropy generation minimization, and the generation of flow architecture, Int. J. Energy Res., Vol. 26, No. 7, pp 0-43, 2002. https://doi.org/10.1002/er.804

[4] Ozgener, L., Hepbasli, A. and Dincer, I., Exergy analysis of two geothermal district heating systems for building applications, Energy Convers. Manag., Vol. 48, pp 1185-1192, 2007.

https://doi.org/10.1016/j.enconman.2006.10.003

[5] Qureshi, B. A. and Zubair, S. M., Application of exergy analysis to various psychometric processes, Int. J. Energy Res., Vol. 27, pp 1079-1094, 2003. https://doi.org/10.1002/er.933

[6] Ratlamwala, T. A. H. and Dincer, I., Efficiency assessment of key psychometric processes, Int. J. Refrig., Vol. 36, pp 1142-1153, 2013. https://doi.org/10.1016/j.ijrefrig.2012.10.038

[7] Franconi, E. M. and Brandemuehl, M. J., Second law study of HVAC distribution system performance, ASHRAE Trans., Vol. 105, No. 1, pp 1237-1246, 1999.

[8] Ghazikhani, M., Khazaee, I. and Vahidifar, S., Exergy analysis of two humidification process methods in air-conditioning systems, Energy Build., Vol. 124, pp 129-140, 2016. https://doi.org/10.1016/j.enbuild.2016.04.077

[9] Caliskan, H., Dincer, I. and Hepbasli, A., Exergetic and sustainability performance comparison of novel and conventional air cooling systems for building applications, Energy Build., Vol. 43, No. 6, pp 14611472, 2011. https://doi.org/10.1016/j.enbuild.2011.02.006

[10] Sakulpipatsin, P., Itard, L. C. M., van der Kooi, H. J., Boelman, E. C. and Luscuere, P. G., An exergy application for analysis of buildings and HVAC systems, Energy Build., Vol. 42, No. 1, pp 90-99, 2010. https://doi.org/10.1016/j.enbuild.2009.07.015

[11] ASHRAE Handbook, Fundamentals, 2009.

[12] Dincer, I. and Rosen M. A., Exergy Analysis of Heating, Refrigerating and Air Conditioning: Methods and Applications, 2015. https://doi.org/10.1016/b978-0-12-417203-6.00008-9

Submitted: $\quad 14.6 .2019$

Accepted: $\quad 20.10 .2019$
Matej Đuranović, mag.ing.mech.

Brod-plin d.o.o

35000 Slavonski Brod

Martina Rauch, mag.ing.mech.

Prof. dr. sc. Antun Galović

Faculty of mechanical engineering and naval architecture

10000 Zagreb

Prof. dr. sc. Marija Živić

Mechanical engineering faculty

35000 Slavonski Brod 